\title{
DESMATAMENTO POR CLASSE DE DECLIVIDADE NO MUNICÍPIO DE IBIRUBA, RS
}

Anilda Back da Silva

Departamento de Engenharia Rural. Centro de Ciēncias Rurais. UFSM. Santa Maria, RS.

RESUMO

Este trabalho teve como objetivo avaliar o desmatamento, relacionando-o, com diferentes classes de declividade, no município de Ibirubā, RS.

Foram elaborados quatro mapas temáticos, um com as classes de declividade e trés com as āreas florestais, correspondentes aos períodos de 1956, 1965 e 1975. O mapa das classes de declividade ba seou-se no mapa de classificação de solos do município e em determi nações de declividades por fotografias aēreas. Os mapas florestais foram feitos usando-se coberturas aerofotogramētricas das trēs da tas citadas.

Os resultados encontrados, para zona original de mata, re velaram que o desmatamento iniciou com maior intensidade na classe de 8 a 15\% de declividade. Apesar da classe de 2 a $8 \%$ oferecer boas condições topogrāficas a agricultura, nela permaneciam as principais reservas florestais, coincidindo com o fundo das propriedades rurais. Estas reservas cederam lugar, gradativamente, a ocupação agrícola es pecialmente no período de 1965 a 1975. Nas classes de declividade in ferior a $2 \%$ e acima de $15 \%$ houve menor desmatamento devido as condi ções topogrāficas pois são terrenos sujeitos a inundações ou muito ingremes.

$\mathrm{Na}$ zona original de campo o desmatamento se fez presente sobre todas as classes de declividade, com maior intensidade onde as condições topogräficas favoreciam a ocupação agrícola ou seja na clas se de declividade de 2 a $8 \%$ e na de 8 a $15 \%$.

SUMMARY

SILVA, A.B. da., 1981. Deforestation through of sloping in Ibirubä,RS: Ciência e Natura (3):75-99.

The present work aims at the evaluation of degree of defo restation, relating it to various classes of sloping in Ibirubā County, State of Rio Grande do Sul, Brazil.

Four maps were drafted: one of them with the degree of slope and three with forest aereas corresponding to the time periods of 1956, 1965 and 1975. The map of slope classes was based upon the soil classification map of the county and on categories of slope obtained through photogrametry. The forest maps were done by using photogrametry 
of the three above dates.

The results show that for the original forest area the de forestation starded more intensively in the class of 8 to $15 \%$ slope. In spite of the 2 to $8 \%$ class offering good topographic and agricul tural conditions, the main forest reserves are found in this area and border on the back 1 ine of rural properties. Such reserves have gradually been used for agricultural activities especially in the period from 1965 to 1975. In the classes of slope less than $2 \%$ and more than $15 \%$ there was less deforestation due to the topographic conditions.

In the original field area the deforestation went over all classes of slope more intensively where the topographical conditions favored the agricultural activity occupation, i.e., in the 2 to $8 \%$ and 8 to $12 \%$ slope classes.

INTRODUÇAO

o desmatamento no Rio Grande do Sul jā excedeu os limites permitidos em todo seu territōrio. Tendo inīcio na época da coloni zação, a retirada de florestas procedeu-se ininterruptamente, para aproveitamento dos produtos da floresta mas especialmente para ocu pação agrícola desses solos. E obvio que para a agricultura,exige-se condições topogrāficas favorāveis principalmente tratando-se de ex tensas lavouras mecanizadas.

RAMBO (7) jā em 1956 observou que no Estado praticamente to dos os terrenos bons haviam perdido sua capa silvātica, restando os trechos imprestäveis nos flancos mais ingremes e rochosos das monta nhas.

observa-se, no entanto, que mesmo em encostas ingremes 0 corre o desmatamento. Assim o objetivo principal do presente traba Tho é relacionar o desmatamento com diferentes classes de declivida de, no município de Ibirubā, RS. Optou-se por esta ārea pelo fato de apresentar coberturas aerofotogramētricas de 1956, 1965 e 1975 e por encontrar-se na região duas paisagens vegetais típicas do Rio Grande do Sul, ou seja, zona original de mata e zona original de cam po.

Por informações colhidas no local sabe-se que o inĩcio da colonização deu-se em 1899 em zona original de mata que segundo RAM BO (8) é representada por "floresta pluvial subtropical" e segundo HUECK (4) é classificada como "mata subtropical perenifolia com mis tura isolada de árvores caducifolias".

Autores como LINDMAN (5) e BATTISTELA (1) referem-se à ex celente qualidade dessas florestas, destacando.se a Araucaria angus tifolia (Pinheiro brasileiro). 
Antigos moradores da região informam que no inīcio da co Ionização, parte da madeira era vendida para Cruz Alta, porém um dos obstāculos à agricultura eram as enormes toras de pinheiros que per maneciam no local e que custavam a decompor.

RAMBO (7) descrevendo a "marcha da colonização no Rio Gran de do Sul, diz que cada qual escolhia o terreno que mais 1 he conten tava os desejos, seja nas imediações dos rios, seja nos vales dos tributārios, construía o primeiro rancho, derrubava o mato ao redor e plantava o primeiro milho entre os troncos ainda fumegantes da quei mada".

RÖHRIG (9), analisando as matas remanescentes no Estado, diz que a maioria é formada por matas espessas compostas de muitís simas árvores fracas e arbustos, quase impenetrāveis, devido a sua vegetação frondosa de bambus e cipōs. Comenta ainda que a existên cia destas florestas ē função da densidade de colonização, a qual, por outro lado, depende das condições naturais como relevo, solo e outros.

MORENO (6) diz que apesar dos solos de mata serem maisfér teis, o topografia constitui-se numa limitação do uso destes solos, pois o excesso da declividade determina o aceleramento da erosão da camada fértil.

MORENO (6) observa ainda que não tendo mais terras contî nuas de mata, os agricultores derrubam as matas de galeria ou os ca pões em zona original de campo e aî implantam suas pequenas culturas, permanecendo os campos com pastagem. Entre as āreas onde aparece es te sistema, o autor cita o Município de Ibirubā. As lavouras em à reas de campo iriam surgir posteriormente.

Segundo o Cödigo Florestal, Lei nọ 4.771 , de 15 de novem bro de 1965, na Região Sul, as derrubadas de florestas nativas, só serão permitidas desde que seja respeitado o limite mínimo de $20 \%$ da ārea de cada propriedade com cobertura arbōrea. Proỉbe tambēm 0 desmatamento das formações florestais onde ocorre o pinheiro bras leiro, tolerandọ-se apenas. a exploração racional destas āreas. 0 artigo 10 refere-se às encostas ingremes, não permitindo derrubadas de florestas em āreas de inclinação entre 25 a 45 graus, sō sendo nelas tolerada a extração de toras quando em regime de utilização ra cional que vise a rendimentos permanentes.

Caracterização geral da ārea

A ārea em estudo consta do municīpio de Ibirubá-RS, loca lizado no Planalto Médio, entre $53^{\circ} 01^{\prime}$ e $53^{\circ} 34^{\prime}$ de longitude oesté e $28^{\circ} 27^{\prime}$ e $28^{\circ} 54^{\prime}$ de latitude sul, conforme a Figura 1. A área total do Municipio è de $778,55 \mathrm{~km}^{2}$. 


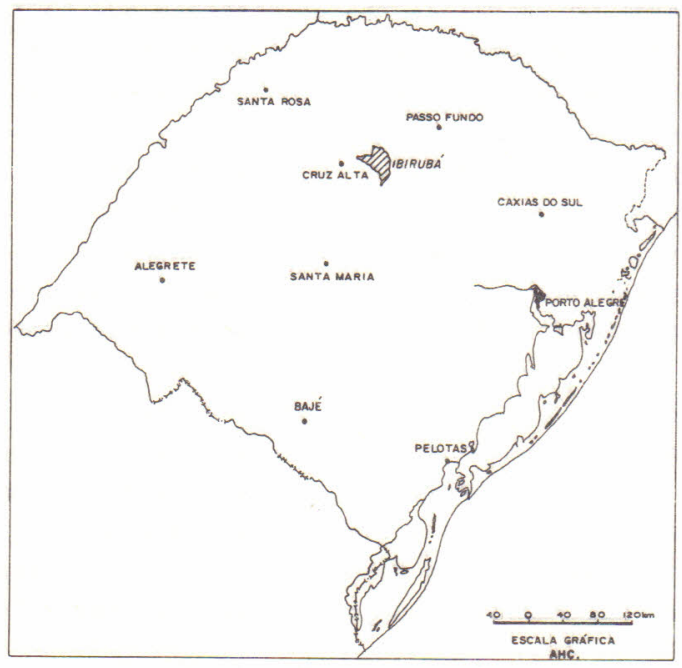

Figura 1. Localização do Municĩpio de Ibirubá, no Estado do Rio Grande do Sul, Brasil.

Geologicamente, a ārea ē constituỉda por derrames de lavas de Formação Serra Geral, porēm, ao sul encontra-se, em menor exten são, a Formação Tupanciretã, segundo BRASIL (3).

Predominam os terrenos ondulados, havendo áreas de encos tas mais ingremes ao longo dos rios Jacuĩ e Jacuĩ-Mirim. As altitu des variam de 320 metros ao sul a 480 metros ao norte.

0 clima é subtropical, com temperatura média anual de $17,5^{\circ} \mathrm{C}$ e precipitação em torno de $1750 \mathrm{~mm}$, com chuvas distribuidas regularmente durante todo 0 ano.

Quanto a cobertura vegetal original, predomina, no munic $\underline{I}$ pio, a zona original de mata que à classificada segundo BRASIL (3) como "floresta latifoliada tropical com presença de Araucäria angus tifolia".

\section{MATERIAIS}

Para confecção do mapa-base, usou-se a carta topográfica em escala 1:100.000 que foi ampliada por pantógrafo para 1:60.000. $\mathrm{Na}$ classificação do relevo do município, segundo suas clas ses de declividade empregou-se o mapa de solos, fotografias e este reoscōpio de espelho com barra de paralaxe.

Utilizou-se ainda para os mapas florestais, trēs cobertu ras aérofotogramétricas de diferentes datas ou seja de 1956, 1965 e 1975 nas escalas aproximadas de 1:30.000, 1:60.000 e 1:20.000, respectivamente. 
Nos trabalhos de fotointerpretação, usou-se estereoscōpio de bolso, mesa de luz e polyester.

Para transferência dos dados fotointerpretados para o ma pa-base, foram usados o Kargl Reflecting Projector - Model RP-T-48 da Keufezz \& Esser $C^{0}$ e o Map-O-Graph-Model 55 da Art-0-Graph Inc.

$\mathrm{Na}$ medição das āreas florestais e da ārea total do municí pio, empregou-se papel milimetrado e o planímetro polar Anster.

\section{METODOS}

Mapa-base

A confecção do mapa-base baseou-se na carta topogrāfica, em escala 1:100.000, levantada pela Diretoria do Serviço Geográfico do Exército. Para delimitap a ārea do Município, usou-se o mapa mu nicipal, alēm de informações locais. Delimitada a ārea sobre a car ta, ampliou-se o mapa, usando-se o pantōgrafo, para 1:60.000, esca la escolhida para os mapas temáticos finais. No mapa-base constaram os seguintes elementos planimétricos: divisa do município, rede de drenagem, estradas, cidade, vilas e povoados.

Fotointerpretacão das Areas Florestais

Aparecendo no Municīpio de Ibirubā, alēm da zona original de Mata, expressiva ārea de campo, considerou-se conveniente estabe lecer o limite entre estas duas zonas.

Esta divisão justifica-se no presente trabalho pois o ti po de cobertura vegetal alēm de sofrer influēncia de inúmeros outros fatores estā também relacionado com o relevo.

o traçado deste limite foi possĩvel, usando-se as fotogra fias aéreas mais antigas e informações colhidas no local.

Antes de iniciar-se os trabalhos de interpretação das äreas florestais, estabeleceu-se uma classificação das florestas existen tes, com as respectiva chave de identificação, dentro das possibili dades oferecidas pela escala das fotografias. Comparou-se as āreas flo restais no campo com as imagens sobre as fotografias, seguindo mēto dos jā apresentados por SERRA FILHO et alii (11). Chegou-se à seguin te classificação:

1. Floresta nativa fechada: formação vegetal de grande porte e que apesar da exploração, conserva alta densidade de copas.

2. Floresta artificial: florestas plantadas e compostas na grande maioria por Eucaliptus spp, aparecendo raros bosques de Pinus spp.

3. Capoeira: vegetação secundāria que sucede a derrubada das flores tas, apresentando porte desde arbustivo até arbōreo.

4. Floresta nativa aberta: formação vegetal de grande porte porém de vido à exploração, apresenta baixa densidade de copas. 
5. Mata ciziar: vegetação arbustiva ou arbōrea de porte médio que se desenvolve ao longo dos cursos d'ägua.

A interpretação das áreas florestais seguiu o método tra dicional, jā descrito por THORLEY et alii (13), usando-se esteoscó pio de bolso e delimitando-se as manchas correspondentes às āreas florestais sobre polyester, fixado sobre a fotografia aērea.

As estradas, rede de drenagem, cidade, villas e povoados fo ram igualmente traçados sobre o transparente para servirem de refe rência na posterior passagem dos dados fotointerpretados para a ma pa-base.

A ārea mínima delimitada foi de 0,36 ha, considerando-se a escala das fotografias e tambēm a definição de ārea florestal, da da por BAUER (2).

Concluídos os trabalhos de interpretação e delimitação das manchas, transferiu-se estes dados para o mapa-base, resultando des ta operação, os três mapas temāticos das āreas florestais, isto é, de 1956, de 1965 e de 1975 (Anexos I, II e III).

Mapas das classes de declividade

0 mapa das classes de declividade (Anexo IV) teve como ori gem o mapa de solos publicado em BRASIL (3). De acordo com esta clas sificação foi possĩvel agrupar as diferentes unidades de solo nas seguintes classes:

- Classe 1: < $2 \%$

- Classe 2: 2 a $8 \%$

- Classe 3: 8 a $15 \%$

- Classe 4: > $15 \%$

Como a classificação de solos é resultante de uma sērie de características. além do relevo, resolveu-se conferir a declividade de inümeras encostas, destacadas dentro de cada classe.

Nesta medição de declividades, feitas sobre fotografias aéreas de 1965, usou-se o método de Stellingnverf, descrito por Rou TIN (10).

Medição de áreas

Concluídos os quatro mapas temáticos procedeu-se à medição das āreas, usando-se papel milimetrado, mëtodo descrito por STRANDBERG (12). Apenas a ärea total do município foi conferida por planímetro.

Apōs obter-se a ārea total do município, mediu-se as āreas por classes de declividade.

Para medir as áreas florestais, colocou-se, inicialmente, sobre mesa de luz, o mapa com as classes de declividade e sobre es te o mapa das āreas florestais. O papel milimetrado, transparente, foi fixado entre os dois mapas. 
A contagem fornecia o nümero de pontos correspondentes a cada parcela de um determinado tipo florestal, dentro de uma classe de declividade.

\section{RESULTADOS E DISCUSSÃO}

Traçando-se o limite entre zona original de Mata e zona original de Campo e calculando-se a ärea total por zona, verificou-se que a zona de mata, ocupa aproximadamente $3 / 4$ partes do município, conforme Tabela I.

TABELA I. AREAS TOTAIS (EMERSAS) DO MUNICÍPIO DE IBIRUBĀ, RS.

\begin{tabular}{lccc}
\hline \multirow{2}{*}{ ZONA } & \multicolumn{2}{c}{ AREA EM HECTARES } \\
\cline { 2 - 3 } & $1956 \mathrm{e}$ & 1965 & 1975 \\
\hline Mata & $57.705,85$ & $54.664,58$ \\
Campo & $20.150,09$ & $20.150,09$ \\
TOTAL & $77.855,94$ & $74.814,67$ \\
\hline
\end{tabular}

O decréscimo da ārea emersa de 1965 a 1975, deve-se ao alagamento, ocorrido neste período, pelas äguas da barragem do Pas so Real; porēm, como ārea total do municīpio considerou-se $778,55 \mathrm{~km}^{2}$.

A Figura 2 mostra um trecho do limite traçado entre zona original de mata e zona original de campo. 0 relevo constitui-se nu ma das referências para a definição desta linha pois era comum a co bertura florestal encontrar-se até a barranca do rio Jacuí-Mirim, em sua margem direita.

Pela Tabela II verifica-se os totais das classes de decli vidade em cada zona, notando-se que na zona de campo a classe com declividade superior a $15 \%$ ē minnima.

TABELA II. AREAS MEDIDAS EM ZONA DE MATA, ZONA DE CAMPO E TOTAL, DE ACORDO COM AS CLASSES DE DECLIVIDADE.

\begin{tabular}{|c|c|c|c|c|c|c|c|}
\hline \multirow{2}{*}{\multicolumn{3}{|c|}{$\underset{\%}{D E C L}$ IVE }} & \multicolumn{5}{|c|}{ AREAS EM HECTARES } \\
\hline & & & \multirow{2}{*}{\multicolumn{2}{|c|}{$\frac{\text { ZONA DE MATA }}{1.528,12}$}} & \multirow{2}{*}{\multicolumn{2}{|c|}{$\frac{\text { ZONA DE CAMPO }}{116,61}$}} & \multirow{2}{*}{$\frac{\text { TOTAL }}{1.644,73}$} \\
\hline & $<$ & 2 & & & & & \\
\hline 2 & a & 8 & 26.576 &, 53 & 7.306 & 21 & $33.882,74$ \\
\hline \multirow[t]{2}{*}{8} & a & 15 & 18.787 &, 38 & 12.030 &, 50 & $30.8,17,88$ \\
\hline & $>$ & 15 & 10.813 &, 82 & 696 & 77 & $11.510,59$ \\
\hline \multicolumn{3}{|c|}{ TOTAL } & 57.705 &, 85 & 20.150 &, 09 & $77.855,94$ \\
\hline
\end{tabular}

Analisando-se a Tabela II, vê-se que o relevo não é muito acidentado; apenas $14 \%$ do município apresenta declividades superiores a $15 \%$. 


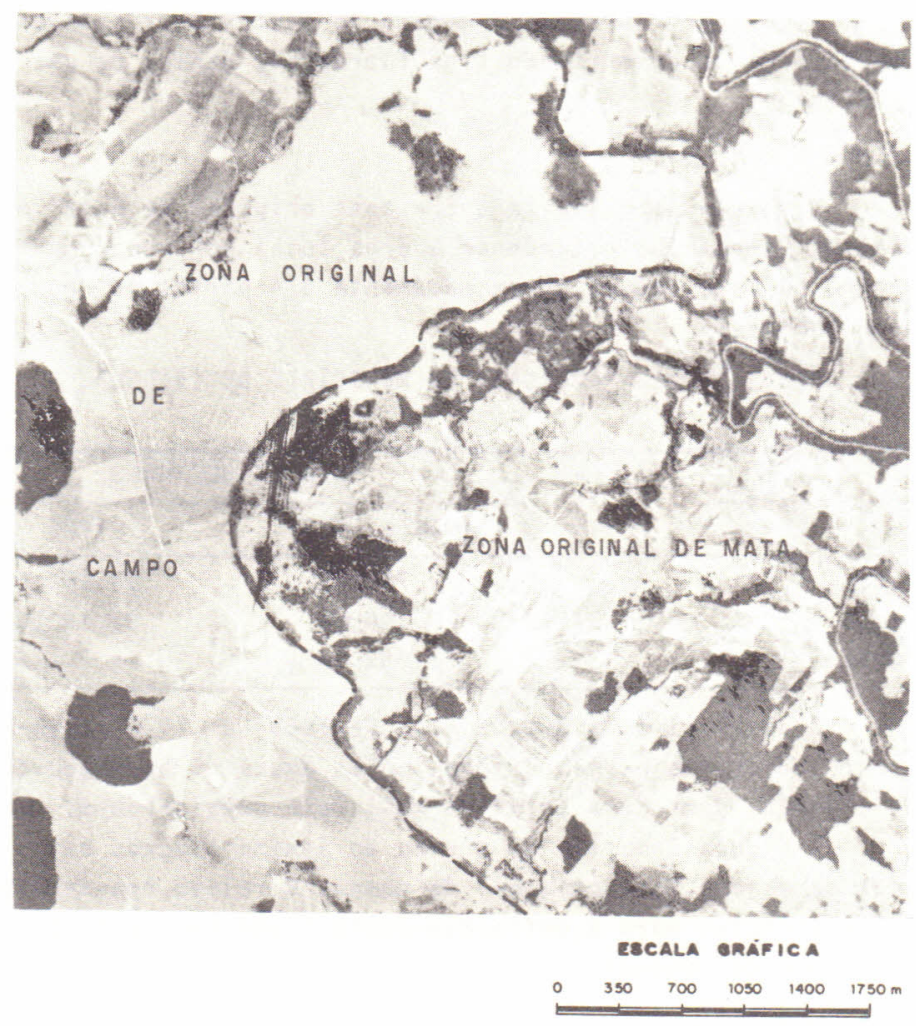

Figura 2. Fotografia aérea de 1965, ilustrando o limite traçado entre zona original de Mata e zona ori ginal de Campo.

Intensidade de desmatamento por classe de declividade

Para facilitar a interpretação dos resultados preferiu-se analisā-los por zona.

Zona originat de mata

Observando-se a Tabela III, nota-se, com clareza, a dimi nuição das āreas florestais em todas as classes de declividade, des tacando-se a de 2 a $8 \%$.

Chama atenção, o fato de a classe de menor cobertura flo restal, jā em 1956, ser a de declividade entre 8 e 15\%. Tambēm em Ibirubá, a classe mais acidentada apresentou a maior percentagem de cobertura florestal, conforme descrições jā feitas por RAMBO ( 7 ) ROHRIG (9) e MORENO (6), para maior parte das āreas íngremes do Estado. 
tABELA III. AREAS FLORESTAIS E PERCENTAGEM DE COBERTURA POR CLASSE DE DECLIVIDADE EM ZONA ORIGINAL DE MATA.

\begin{tabular}{|c|c|c|c|c|c|c|c|}
\hline \multirow{3}{*}{\multicolumn{2}{|c|}{$\begin{array}{c}\text { CLASSE } \\
\text { DE } \\
\text { DECLIVI } \\
\text { DADE } \\
(\%)\end{array}$}} & \multicolumn{6}{|c|}{ PERIODOS } \\
\hline & & \multicolumn{2}{|c|}{1956} & \multicolumn{2}{|c|}{1965} & \multicolumn{2}{|c|}{1975} \\
\hline & & $\begin{array}{l}\text { Area de } \\
\text { Florestas } \\
\text { (ha) }\end{array}$ & $\begin{array}{l}\text { \% sobre } \\
\text { Arrea To } \\
\text { tal da } \\
\text { classe }\end{array}$ & $\begin{array}{c}\text { Area de } \\
\text { Florestas } \\
\text { (ha) }\end{array}$ & $\begin{array}{l}\text { \% sobre } \\
\text { Area To } \\
\text { tal da } \\
\text { Classe }\end{array}$ & $\begin{array}{l}\text { Area de } \\
\text { Florestas } \\
\text { (ha) }\end{array}$ & $\begin{array}{l}\% \text { sobre } \\
\text { Area To } \\
\text { tal da } \\
\text { classe }\end{array}$ \\
\hline & $a<$ & 293,12 & 19,18 & 260,16 & 17,02 & 194,94 & 15,54 \\
\hline 2 & a 8 & $6.407,92$ & 24,11 & $4.687,86$ & 17,63 & $2.288,03$ & 9,12 \\
\hline \multirow[t]{2}{*}{8} & a 15 & $2.897,92$ & 15,41 & $2.149,71$ & 11,43 & $1.434,45$ & 7,97 \\
\hline & $>15$ & $3.271,69$ & 30,25 . & $2.745,28$ & 25,39 & $2.252,20$ & 21,80 \\
\hline & $O T A L$ & $12.870,66$ & 22,30 & $9.843,22$ & 17,06 & $6.169,62$ & 11,29 \\
\hline
\end{tabular}

Noção mais nîtida sobre a intensidade de desmatamento re lacionado com as classes de declividade, tem-se, ao analisar a Figu ra 3. Aqui, consideraram-se as āreas florestais existentes em 1956 como um valor de 100\%. Os resultados de 1965 e de 1975 foram compa rados com os de 1956 .

Classe de declividade inferior a $2 \%$

A menor alteração das āreas florestais, na zona de mata, ocorreu na classe de declividade inferior a $2 \%$, classe esta que tam bém representa a menor extensão dentro do Município. A Tabela IV re laciona a ārea e percentagem de cobertura dos tipos florestais nes ta classe de declividade. Convēm lembrar que os nūmeros de 1 a 5 i dentificam os tipos florestais já descritos no capítulo "Métodos". 0 tipo 5 correspondente a Mata Ciliar foi somado ao tipo l que é Ma ta Nativa Fechada, por dificuldade de interpretação sobre as fotogra fias na escala $1: 60.000$.

TABELA IV. AREA E PERCENTAGEM DE COBERTURA DOS TIPOS FLORESTAIS NA CLASSE DE DECLIVIDADE INFERIOR A $2 \%$ EM ZONA ORIGINAL DE MATA.

\begin{tabular}{|c|c|c|c|c|c|c|}
\hline \multirow[b]{3}{*}{$\begin{array}{l}\text { TIPOS } \\
\text { FLORES } \\
\text { TAIS }\end{array}$} & \multicolumn{6}{|c|}{ PERIODOS } \\
\hline & \multicolumn{2}{|c|}{1956} & \multicolumn{2}{|c|}{1965} & \multicolumn{2}{|c|}{1975} \\
\hline & $\begin{array}{c}\text { Area de } \\
\text { Florestas } \\
\text { (ha) }\end{array}$ & $\begin{array}{l}\text { \% sobre } \\
\text { Area To } \\
\text { tal da } \\
\text { Classe }\end{array}$ & \begin{tabular}{|c|}
$\begin{array}{c}\text { Area de } \\
\text { Florestas } \\
\text { (ha) }\end{array}$ \\
\end{tabular} & $\begin{array}{l}\text { \% sobre } \\
\text { Area To } \\
\text { tal da } \\
\text { Classe }\end{array}$ & $\begin{array}{l}\text { Area de } \\
\text { Florestas } \\
\text { (ha) }\end{array}$ & $\begin{array}{l}\text { \% sobre } \\
\text { Area To } \\
\text { tal da } \\
\text { Classe }\end{array}$ \\
\hline $\begin{array}{l}(1)+(5) \\
(2) \\
(3) \\
(4) \\
\text { T } 0 \text { T A L }\end{array}$ & $\begin{array}{r}269,12 \\
0,72 \\
15,05 \\
8,24 \\
293,12\end{array}$ & $\begin{array}{r}17,61 \\
0,05 \\
0,98 \\
0,54 \\
19,18\end{array}$ & $\begin{array}{c}248,33 \\
0,36 \\
\vdots \\
11,47 \\
260,16\end{array}$ & $\begin{array}{c}16,25 \\
0,02 \\
- \\
0,75 \\
17,02\end{array}$ & $\begin{array}{r}186,34 \\
0,72 \\
- \\
7,88 \\
194,94\end{array}$ & $\begin{array}{r}14,85 \\
0,06 \\
- \\
0,63 \\
15,54\end{array}$ \\
\hline
\end{tabular}




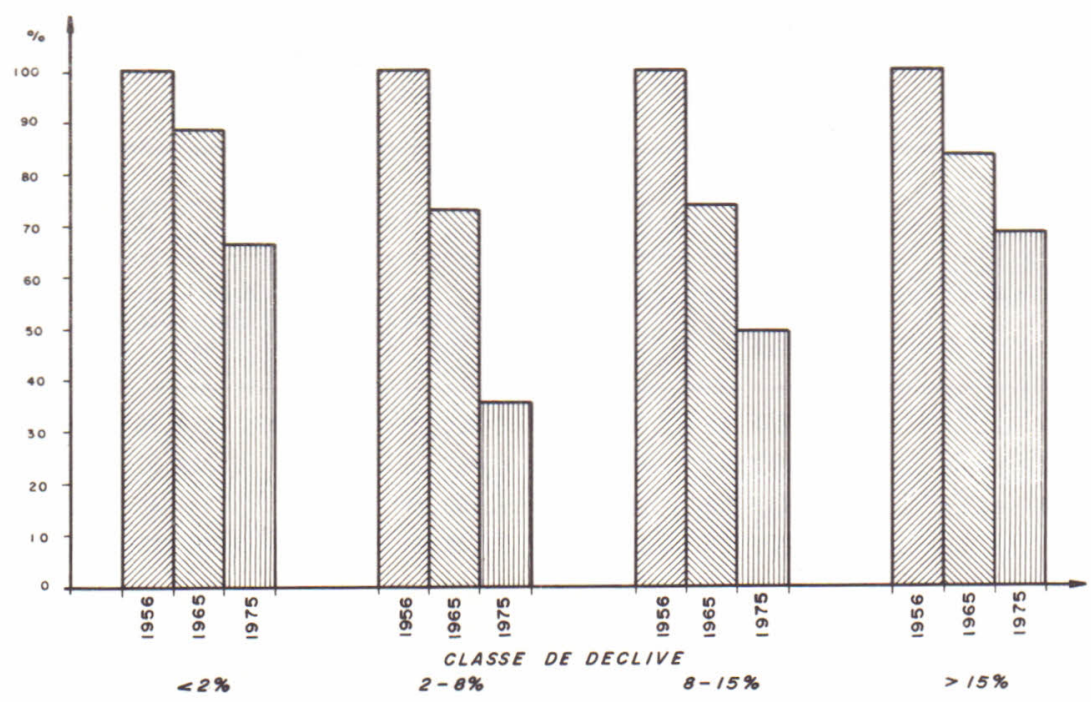

Figura 3. Desmatamento por classe de declividade, considerando-se a ārea de florestas de 1956, como 100\% - Zona Original de Mata.

Em geral, a classe de declividade inferior a $2 \%$ está cons tituída por terrenos situados a margem dos cursos d'água e em gran de parte sujeitos a inundações. As āreas florestais são formadas es pecialmente por matas ciliares. Estas razóes citadas, quanto as con dições de topografia e qualidade das matas, devem ter contribuído pa ra o pequeno desmatamento nesta classe.

Classe de declividade de 2 a $8 \%$

Pela análise dos valores apresentados na Tabela $V$, vê-se que foi nesta classe que ocorreu o maior desmatamento durante o pe ríodo em estudo. E esta classe, a mais expressiva em ārea, correspon dendo a $46 \%$ de tuda a zona original de mata.

TABELA $V$. AREA E PERCENTAGEM DE COBERTURA DOS TIPOS FLORESTAIS NA CLASSE DE DECLIVIDADE DE $2 \%$ A $8 \%$, EM ZONA ORIGINAL DE MATA.

\begin{tabular}{|c|c|c|c|c|c|c|}
\hline \multirow{3}{*}{$\begin{array}{l}\text { TIPOS } \\
\text { FLORES } \\
\text { TAIS }\end{array}$} & \multicolumn{6}{|c|}{ PERIODOS } \\
\hline & \multicolumn{2}{|c|}{1956} & \multicolumn{2}{|c|}{1965} & \multicolumn{2}{|c|}{1975} \\
\hline & $\begin{array}{c}\text { Area de } \\
\text { Florestas } \\
\text { (ha) }\end{array}$ & $\begin{array}{l}\text { \% sobre } \\
\text { Area To } \\
\text { tal da } \\
\text { Classe }\end{array}$ & $\begin{array}{c}\text { Area de } \\
\text { Florestas } \\
\text { (ha) }\end{array}$ & $\begin{array}{l}\text { \% sobre } \\
\text { Area To } \\
\text { tal da } \\
\text { Classe }\end{array}$ & $\begin{array}{c}\text { Area de } \\
\text { Florestas } \\
\text { (ha) }\end{array}$ & $\begin{array}{l}\text { \% sobre } \\
\text { Area To } \\
\text { tal da } \\
\text { Classe }\end{array}$ \\
\hline 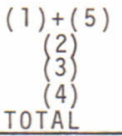 & $\begin{array}{r}5.754,66 \\
7,17 \\
358,70 \\
287,39 \\
6.407,92 \\
\end{array}$ & $\begin{array}{r}21,65 \\
0,03 \\
1,35 \\
1,08 \\
24,11\end{array}$ & $\begin{array}{r}4.368,94 \\
16,48 \\
160,54 \\
141,90 \\
4.687,86\end{array}$ & $\begin{array}{r}16,44 \\
0,06 \\
0,60 \\
0,53 \\
17,63\end{array}$ & $\begin{array}{r}1.809,28 \\
55,54 \\
154,80 \\
268,40 \\
2.288,03\end{array}$ & $\begin{array}{l}7,21 \\
0,22 \\
0,62 \\
1,07 \\
9,12\end{array}$ \\
\hline
\end{tabular}


Os terrenos da classe entre 2 a $8 \%$, situados nos topos das elevações em forma de coxilhas, incluindo os divisores d'ägua dos principais cursos, conservavam, em 1956, a percentagem de $24 \%$ de co bertura florestal e as maiores parcelas florestais. Segundo informa ções obtidas na região, este fato estā relacionado com o sistema de colonização, encontrando-se, em geral nestes terrenos, o fundo da propriedade rural com as reservas florestais, permanecendo estas, portanto, longe das sedes.

Verifica-se que a redução das āreas florestais de 1965 pa ra 1975 foi maior do que entre o período de 1956 a 1965. Pela anāli se das fotografias aéreas como por observações no local,verificou-se a intensa ocupação agrīcola destas āreas recentemente desmatadas.

Classe de declividade de 8 a $15 \%$

Pela Tabela VI, conclui-se que foi nesta classe onde ocor reu, inicialmente, o maior desmatamento, pois já em 1956, apresenta va a menor percentagem de cobertura florestal, conservando atē 1975 os menores indices.

TABELA VI. AREA E PERCENTAGEM DE COBERTURA DOS TIPOS FLORESTAIS NA CLASSE DE DECLIVIDADE ENTRE 8\% E 15\%, EM ZONA ORIGINAL DE MATA.

\begin{tabular}{|c|c|c|c|c|c|c|}
\hline \multirow{3}{*}{$\begin{array}{l}\text { TIPOS } \\
\text { FLORES } \\
\text { TAIS }\end{array}$} & \multicolumn{6}{|c|}{ PERIODOS } \\
\hline & \multicolumn{2}{|c|}{1956} & \multicolumn{2}{|c|}{1965} & \multicolumn{2}{|c|}{1975} \\
\hline & $\begin{array}{c}\text { Area de } \\
\text { Florestas } \\
\text { (ha) }\end{array}$ & $\begin{array}{l}\% \text { sobre } \\
\text { Area To } \\
\text { tal da } \\
\text { Classe }\end{array}$ & $\begin{array}{c}\text { Area de } \\
\text { Florestas } \\
\text { (ha) }\end{array}$ & $\begin{array}{l}\text { \% sobre } \\
\text { Area To } \\
\text { tal da } \\
\text { Classe }\end{array}$ & $\begin{array}{c}\text { Area de } \\
\text { Florestas } \\
\text { (ha) }\end{array}$ & $\begin{array}{l}\text { \% sobre } \\
\text { Area To } \\
\text { tal da } \\
\text { Classe }\end{array}$ \\
\hline$(1)+(5)$ & $2.430,29$ & 12,93 & $1.903,53$ & 10,13 & $1.034,84$ & 5,78 \\
\hline (2) & 13,97 & 0,07 & 15,41 & 0,08 & 69,16 & 0,38 \\
\hline (3) & 153,01 & 0,81 & 79,55 & 0,42 & 70,23 & 0,39 \\
\hline (4) & 300,65 & 1,60 & 151,22 & 0,80 & 256,22 & 1,42 \\
\hline TOTAL & $2.897,92$ & 15,41 & $2.149,71$ & 11,43 & $1.434,45$ & 7,97 \\
\hline
\end{tabular}

Verificando a localização desta classe de declividade, vêse que esta ārea deve ter sido desmatada em primeiro lugar, para cons trução das sedes de propriedades rurais e para as primeiras lavou ras. Isto porque estas terras, em geral, situam-se nas encostas, prō ximas aos cursos d'āgua, fato jā descrito por RAMBO (7) para outras āreas de colonização no Rio Grande do Sul. Esta posição das casas rurais pode ser observada nitidamente sobre as fotografias aēreas de 1956. 
Classe de declividade acima de $15 \%$

Confirmando as observações feitas por RAMBO (7), ROHRIG (9)

e MORENO (6) para a maioria dos terrenos mais íngremes do Estado do Rio Grande do Sul, tambēm no municīpio de Ibirubā permanece a clas se de maior declividade, com a maior percentagem de cobertura flo restal, conforme indica a Tabela VII.

TABELA VII. AREA E PERCENTAGEM DE COBERTURA DOS TIPOS FLORESTAIS NA CLASSE DE DECLIVIDADE ACIMA DE 15\%, EM ZONA ORIGINAL DE MATA

\begin{tabular}{|c|c|c|c|c|c|c|}
\hline \multirow{3}{*}{$\begin{array}{l}\text { TIPOS } \\
\text { FLORES } \\
\text { TAIS }\end{array}$} & \multicolumn{6}{|c|}{ PERIODOS } \\
\hline & \multicolumn{2}{|c|}{1956} & \multicolumn{2}{|c|}{1965} & \multicolumn{2}{|c|}{1975} \\
\hline & $\mid \begin{array}{c}\text { Area de } \\
\text { Florestas } \\
\text { (ha) }\end{array}$ & $\begin{array}{l}\text { \% sobre } \\
\text { Area } \\
\text { tal } 10 \\
\text { Classe }\end{array}$ & $\begin{array}{c}\text { Area de } \\
\text { Florestas } \\
\text { (ha) }\end{array}$ & $\begin{array}{l}\text { \% sobre } \\
\text { Area To } \\
\text { tal da } \\
\text { Classe }\end{array}$ & $\begin{array}{c}\text { Area de } \\
\text { Florestas } \\
\text { (ha) }\end{array}$ & $\begin{array}{l}\text { \% sobre } \\
\text { Area To } \\
\text { tal da } \\
\text { Classe }\end{array}$ \\
\hline$(1)+(5)$ & $2.686,87$ & 24,85 & $2.397,33$ & 22,17 & $1.741,56$ & 16,86 \\
\hline (2) & - & - & - & - & 2,51 & 0,02 \\
\hline (3) & 498,82 & 4,61 & 307,10 & 2,84 & 272,70 & 2,64 \\
\hline (4) & 86,00 & 0,79 & 40,85 & 0,38 & 235,43 & 2,28 \\
\hline TOTAL & $3.271,69$ & 30,25 & $2.745,28$ & 25,39 & $2.252,20$ & 21,80 \\
\hline
\end{tabular}

Os terrenos representados por esta classe são constituí dos na sua maioria por encostas ingremes, por vezes com declividades de atē 30 ou $40 \%$. Encontra-se esta classe especialmente nas encos tas do vale do rio Jacuí-Mirim e em parte às margens do rio Jacuí.

Mesmo sendo uma classe com fortes declividades, também ne le verificou-se uma diminuição das florestas.

Pela anālise das fotografias aēreas, verificou-se que nes tas encostas īngremes, certas āreas florestais que em 1956 apresen tavam alta densidade, mostravam baixa densidade em 1975. Isso expli ca a exploração destas florestas sem no entanto haver retirada total.

Zona original de campo

Em zona original de campo, o desmatamento também ocorreu sobre todas as classes de declividade, conforme indicam os dados da Tabela VIII.

Proporcionalmente aos valores existentes em 1956, verifi ca-se, pela Figura 4 que as maiores reduções ocorreram nas classes de declividade de 2 a $8 \%$ e de declividades superiores a $15 \%$

Classe de declividade menor que $2 \%$

A classe de declividade inferior a $2 \%$, apresenta uma área 
TABELA VIII. AREAS FLORESTAIS E PERCENTAGEM DE COBERTURA POR CLASSE DE DECLIVIDADE EM ZONA ORIGINAL DE CAMPO

\begin{tabular}{|c|c|c|c|c|c|c|c|}
\hline \multirow{3}{*}{$\begin{array}{l}\text { CLASSE } \\
\text { DE } \\
\text { DECLIVI } \\
\text { DADE } \\
(\%)\end{array}$} & \multirow{3}{*}{$\begin{array}{c}\text { AREA TO } \\
\text { TAL DA } \\
\text { CLASSE } \\
\text { (ha) }\end{array}$} & \multicolumn{6}{|c|}{ PERIODOS } \\
\hline & & \multicolumn{2}{|c|}{1956} & \multicolumn{2}{|c|}{1965} & \multicolumn{2}{|c|}{1975} \\
\hline & & $\begin{array}{c}\text { Area de } \\
\text { Flores- } \\
\text { tas } \\
\text { (ha) }\end{array}$ & $\begin{array}{l}\% \text { sobre } \\
\text { Area To } \\
\text { tal da } \\
\text { Classe }\end{array}$ & $\begin{array}{c}\text { Area de } \\
\text { Flores- } \\
\text { tas } \\
\text { (ha) }\end{array}$ & $\begin{array}{l}\text { \% sobre } \\
\text { Area To } \\
\text { tal da } \\
\text { Classe }\end{array}$ & $\begin{array}{c}\text { Area de } \\
\text { Flores- } \\
\text { tas } \\
\text { (ha) }\end{array}$ & $\begin{array}{l}\text { \% sobre } \\
\text { Area To } \\
\text { tal da } \\
\text { Classe }\end{array}$ \\
\hline$<2$ & 116,61 & 12,18 & 10,44 & 11,47 & 9,83 & 11,47 & 9,83 \\
\hline 2 a 8 & $7.306,21$ & 544,33 & 7,45 & 457,25 & 6,25 & 294,92 & 4,03 \\
\hline 8 a 15 & $12.030,50$ & $1.480,32$ & 12,30 & $1.306,16$ & 10,85 & $1.186,12$ & 9,86 \\
\hline$>15$ & 696,77 & 216,80 & 31,11 & 147,99 & 21,23 & 130,79 & 18,77 \\
\hline TOTAL & $20.150,09$ & $2.253,63$ & 11,18 & $1.922,87$ & 9,54 & $1.623,30$ & 8,06 \\
\hline
\end{tabular}

mínima, situada às margens de cursos d'água. Por ser constituída de terrenos muito úmidos apresenta pequena redução das āreas de mata conforme Tabela IX.

TABELA IX. AREA E PERCENTAGEM DE COBERTURA DOS TIPOS FLORESTAIS NA CLASSE DE DECLIVIDADE INFERIOR A $2 \%$, EM ZONA ORIGINAL DE CAMP 0

\begin{tabular}{|c|c|c|c|c|c|c|}
\hline \multirow{3}{*}{$\begin{array}{l}\text { TIPOS } \\
\text { FLORES } \\
\text { TAIS }\end{array}$} & \multicolumn{6}{|c|}{ PERIODOS } \\
\hline & \multicolumn{2}{|c|}{1956} & \multicolumn{2}{|c|}{1965} & \multicolumn{2}{|c|}{1975} \\
\hline & $\begin{array}{c}\text { Area de } \\
\text { Florestas } \\
\text { (ha) }\end{array}$ & $\begin{array}{l}\text { \% sobre } \\
\text { Area To } \\
\text { tal dal } \\
\text { Classe }\end{array}$ & \begin{tabular}{|c|} 
Area de \\
Florestas \\
(ha)
\end{tabular} & $\begin{array}{l}\text { \% sobre } \\
\text { Area To } \\
\text { tal da } \\
\text { Classe }\end{array}$ & $\begin{array}{c}\text { Area de } \\
\text { Florestas } \\
\text { (ha) }\end{array}$ & $\begin{array}{l}\text { \% sobre } \\
\text { Area To } \\
\text { tal da } \\
\text { Classe }\end{array}$ \\
\hline$(1)+(5)$ & 12,18 & 10,44 & 11,47 & 9,83 & 11,47 & 9,83 \\
\hline (2) & - & - & - & - & - & - \\
\hline (3) & - & - & - & - & - & - \\
\hline (4) & - & - & - & - & - & - \\
\hline TOTAL & 12,18 & 10,44 & 11,47 & 9,83 & 11,47 & 9,83 \\
\hline
\end{tabular}

\section{Crasse de dectividade de 2 a $8 \%$}

Em zona de campo, no Município, é esta a classe que apre senta a menor percentagem de cobertura florestal, segundo a Tabela $X$.

Os terrenos são representados, nesta classe, especialmente pelos topos das coxilhas, onde a vegetação arbōrea se torna escassa.

o principal desmatamento que contribuiu para os indices a presentados entre 1965 e 1975, ocorreu na região da Fazenda Itaíba, onde grande parte das florestas derrubadas achava-se sobre estaclas se de declividade. 


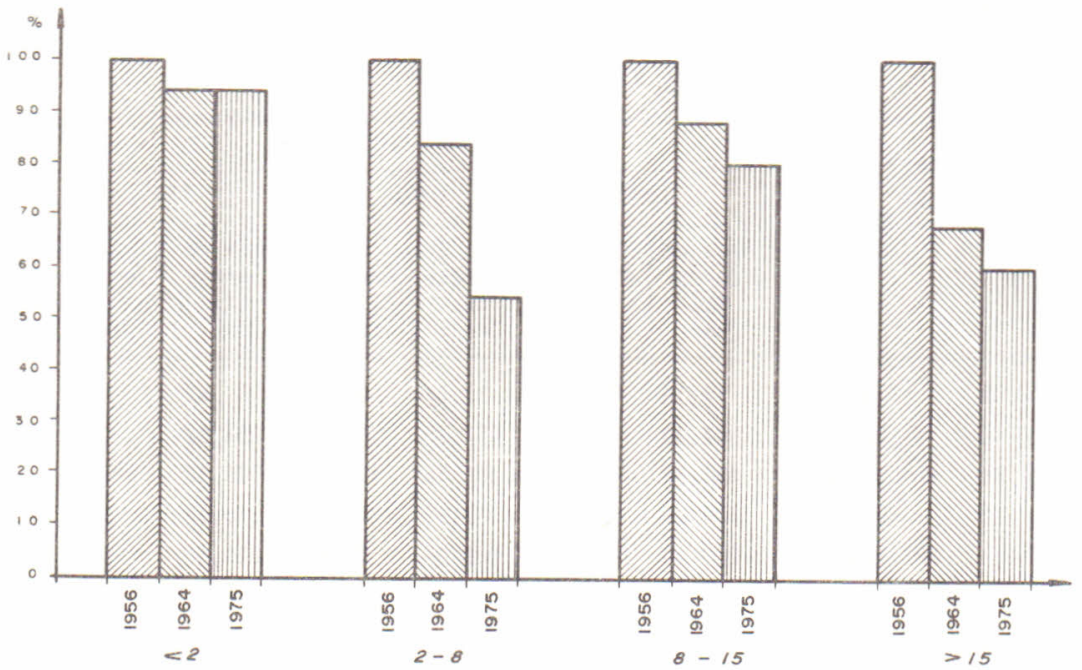

Figura 4. Desmatamento por classe de declividade, considerando-se a ārea de florestas de 1956, como 100\% - Zona Original de Campo.

TABELA X. AREA E PERCENTAGEM DE COBERTURA DOS TIPOS FLORSTAIS NA CLAS SE DE DECLIVIDADE DE 2\% A $8 \%$, EM ZONA ORIGINAL DE CAMPO

\begin{tabular}{|c|c|c|c|c|c|c|}
\hline \multirow{3}{*}{$\begin{array}{l}\text { TIPOS } \\
\text { FLORES } \\
\text { TAIS }\end{array}$} & \multicolumn{6}{|c|}{ PERIODOS } \\
\hline & \multicolumn{2}{|c|}{1956} & \multicolumn{2}{|c|}{1965} & \multicolumn{2}{|c|}{1975} \\
\hline & \begin{tabular}{|c} 
Area de \\
Florestas \\
(ha)
\end{tabular} & $\begin{array}{l}\text { \% sobre } \\
\text { Area To } \\
\text { tal da } \\
\text { Classe }\end{array}$ & \begin{tabular}{|c|} 
Area de \\
Flores tas \\
(ha)
\end{tabular} & $\begin{array}{l}\text { \% sobre } \\
\text { Area To } \\
\text { tal da } \\
\text { Classe }\end{array}$ & \begin{tabular}{|c} 
Area de \\
Flores tas \\
(ha)
\end{tabular} & $\begin{array}{l}\text { \% sobre } \\
\text { Area To } \\
\text { tal da } \\
\text { Classe }\end{array}$ \\
\hline \multirow[t]{5}{*}{$(1)+(5)$} & 459,40 & 6,29 & 403,50 & 5,52 & 239,32 & 3,28 \\
\hline & 0,72 & 0,01 & 0,36 & 0,004 & 1,79 & 0,02 \\
\hline & 29,03 & 0,40 & 16,84 & 0,23 & 9,67 & 0,13 \\
\hline & 55,18 & 0,75 & 36,55 & 0,50 & 44,08 & 0,60 \\
\hline & 544,33 & 7,45 & 457,25 & 6,254 & 294,92 & 4,03 \\
\hline
\end{tabular}

Em parte, a derrubada da cobertura florestal nesta classe, deve-se tambēm à ocupação agrícola que vem-se extendendo intensamen te nesta ārea.

Classe de declividade de 8 a $15 \%$

E nesta classe que se encontra a maior quantidade de vege tação arbōrea típica de zona de campo. Os resultados estão represen tados na Tabela XI. 
TABELA Xi. AREA E PERCENTAGEM DE COBERTURA DOS TIPOS FLORESTAIS NA CLASSE DE DECLIVIDADE DE $8 \%$ A $15 \%$, EM ZONA ORIGINAL DE CAM PO.

\begin{tabular}{|c|c|c|c|c|c|c|}
\hline \multirow{3}{*}{$\begin{array}{l}\text { TIPOS } \\
\text { FLORES } \\
\text { TAIS }\end{array}$} & \multicolumn{6}{|c|}{ PERIODOS } \\
\hline & \multicolumn{2}{|c|}{1956} & \multicolumn{2}{|c|}{1965} & \multicolumn{2}{|c|}{1975} \\
\hline & $\mid \begin{array}{c}\text { Area de } \\
\text { Florestas } \\
\text { (ha) }\end{array}$ & $\begin{array}{l}\text { \% sobre } \\
\text { Area To } \\
\text { tal da } \\
\text { Classe }\end{array}$ & $\begin{array}{c}\text { Area de } \\
\text { Florestas } \\
\text { (ha) }\end{array}$ & $\begin{array}{l}\text { \% sobre } \\
\text { Area To } \\
\text { tal da } \\
\text { Classe }\end{array}$ & \begin{tabular}{|c} 
Area de \\
Florestas \\
(ha)
\end{tabular} & $\begin{array}{l}\% \text { sobre } \\
\text { Area To } \\
\text { tal da } \\
\text { Classe }\end{array}$ \\
\hline$(1)+(5)$ & $1.310,11$ & 10,89 & $1.164,66$ & 9,68 & $1.067,15$ & 8,87 \\
\hline (2) & 0,36 & 0,003 & 0,36 & 0,003 & 8,60 & 0,07 \\
\hline (3) & 70,95 & 0,59 & 45,87 & 0,38 & 4,66 & 0,04 \\
\hline (4) & 98,90 & 0,82 & 95,32 & 0,79 & 105,71 & 0,88 \\
\hline TOTAL & $1.480,32$ & 12,303 & $1.306,16$ & 10,853 & $1.186,12$ & 9,86 \\
\hline
\end{tabular}

Pela Tabela II verifica-se que estes terrenos representam a maior extensão na zona de campo no Município e formam vertentes consideravelmente longas às margens dos cursos d'água. Esta classe de declividade está representada também pela maior parte dos terre nos na divisa com Cruz Alta, onde a vegetação se conserva pratica mente inalterada.

As maiores modificações ocorreram ou na zona de transição entre campo e floresta ou na Fazenda Itaíba, onde diversas áreas flo restais existentes em 1965 desapareceram em 1975.

Classe de declividade acima de 15\%

Mesmo sendo pequena a extensão representada por esta clas se, houve diminuição da ārea florestal, especialmente de 1956 a 1965, cujos dados estão representados na Tabela XII.

TABELA XII. AREA E PERCENTAGEM DE COBERTURA DOS TIPOS FLORESTAIS NA CLASSE DE DECLIVIDADE ACIMA DE 15\% EM ZONA ORIGINAL DE CAMPO.

\begin{tabular}{|c|c|c|c|c|c|c|}
\hline \multirow[b]{3}{*}{$\begin{array}{l}\text { TIPOS } \\
\text { FLORES } \\
\text { TAIS }\end{array}$} & \multicolumn{6}{|c|}{ PERIODOS } \\
\hline & \multicolumn{2}{|c|}{1956} & \multicolumn{2}{|c|}{1965} & \multicolumn{2}{|c|}{1975} \\
\hline & $\mid \begin{array}{cr}\text { Area de } \\
\text { Florestas } \\
\text { (ha) }\end{array}$ & $\begin{array}{l}\text { \% sobre } \\
\text { Area To } \\
\text { tal da } \\
\text { Classe }\end{array}$ & $\begin{array}{c}\text { Area de } \\
\text { Florestas } \\
\text { (ha) }\end{array}$ & $\begin{array}{l}\text { \% sobre } \\
\text { Area To } \\
\text { tal da } \\
\text { Classe }\end{array}$ & \begin{tabular}{|c|}
$\begin{array}{c}\text { Area de } \\
\text { Florestas } \\
\text { (ha) }\end{array}$ \\
\end{tabular} & $\begin{array}{l}\text { \% sobre } \\
\text { Area To } \\
\text { tal da } \\
\text { Classe }\end{array}$ \\
\hline$(1)+(5)$ & 112,52 & 16,15 & 96,62 & 14,29 & 45,51 & 6,53 \\
\hline (2) & - & - & - & - & 1,79 & 0,26 \\
\hline (3) & 101,77 & 14,60 & 48,38 & 6,94 & 55,18 & 7,92 \\
\hline (4) & 2,51 & 0,36 & - & - & 28,31 & 4,06 \\
\hline TOTAL & 216,80 & 31,11 & 147,99 & 21,23 & 130,79 & 18,77 \\
\hline
\end{tabular}


Este terrenos encontram-se nas encostas ingremes dos vales de certos cursos d'água, localizados ao norte do Município, confor me ilustra o Anexo IV.

Pela anālise dos mapas e da tabela anterior, vê-se que a principal alteração ocorreu entre 1956 e 1965 e estā representada por certas manchas de capoeira, existentes em 1956 e não mais encon tradas em 1965. Já no período de 1965 a 1975 a maior redução deu-se na ārea de mata nativa fechada e mata ciliar.

\section{CONCLUSOES}

A avaliação do desmatamento relacionado com as classes de declividade em zona de mata original no município de Ibirubá, RS mos trou que a classe de 8 a $15 \%$ de declividade, foi a primeira a ser desmatada devido ao sistema de colonização. Apesar da retirada de florestas até 1956 ter sido bastante generalizada, as principais re servas permaneciam sobre a classe de 2 a $8 \%$ de declividade coinci dindo com o fundo das propriedades rurais, mas foram gradativamente cedendo lugar a ocupação agrícola principalmente entre 1965 e 1975. A classe de declividade inferior a $2 \%$, por apresentar pouco interes se à exploração agrīcola, sendo sujeita a inundações, permaneceu com maior cobertura florestal. Em regiões de declividade acima de $15 \%$, apesar de tambēm ocorrer desmatamento, o fator topogrāfico dificul tou a substituição das āreas florestais por cultivos agrīcolas; con tudo, observou-se que as reservas florestais estão bastante explora das, permanecendo uma vegetação de menor valor econômico.

Apesar da zona de campo apresentar pequena área florestal houve ainda, de 1956 a 1975 , desmatamento de 630 ha, sendo 294 ha da classe de 8 a $15 \%, 250$ ha na de 2 a $8 \%$ e 86 ha na de declividade acima de $15 \%$. Também nesta zona, o fator ocupação agrícola, explica a preferência de desmatamento nas āreas que oferecem melhores condi ções topogräficas às lavouras.

\section{BIBLIOGRAFIA CITADA}

1. Battistella, V. História de tapera. Campo Real, Impressão GESA, 1972. $233 \mathrm{p}$.

2. BAUER, F.W. Walbau als wissenschaft. Munchen Basel Wiene, BLV Ver lagsgeselschaft, 1962. $182 \mathrm{p}$.

3. BRASIL, Instituto Nacional de Colonização e Reforma Agrāria. Se cretaria da Agricultura do Rio Grande do Sul e Faculdade de Agronomia da UFRGS. Levantamento e utilizagão agricola dos so Ios do Municipio de Ibirubá. Porto Alegre, Mimeografado, 1970, 70p.

4. HUECK, K. As florestas da América do Sul. São Paulo, Editora da Universidade de Brasillia e Ed. Polígono, 1972, 466 p. 
5. LINDMAN, C.A.M. \& FERRI, M.G. A vegetąão no Rio Grande do Sul. Belo Horizonte, Ed. Itatiaia e Ed. da USP, 1974. 377 p. (Tra dução em 1906 por Alberto Lofgren, Porto Alegre. Original Sue co, 1900. Ampliada por Ferri).

6. MORENo, J.A. Uso da terra, vegetação original e atual do Rio Grande do Sul. Boletim Geogräfico do RGS. Porto Alegre, 17 (15): 45-51, jan/dez. 1972 .

7. RAMBO, B.S.J. A fisionomia do Rio Grande do Sul. 2. ed. Porto Alegre, Livraria Selbach, 1956. $475 \mathrm{p}$.

8. RAMBO, B. A imigração da selva higrófila no Rio Grande do Sul. Igajaî, Anais Botânicos, 3. Herbārio "Barbosa Rodrigues".

9. RÖHRIG, E. As condigões florestais do Estado do Rio Grande do Suz. Reinhausen, R. F. Alemanha, Relatōrio 3401, Mimeografá do, 1969. 45 p.

10. ROUTIN, D.D. \& FOREDO, J.A.M. Instrumentos fotogramétricos apro ximados. Bogotā, Centro Interamericano de Fotointerpretaciōn, 1972. $132 \mathrm{p}$.

11. SERRA FILHO, R. et alii. Levantamento da cobertura vegetal natu rat e do reflorestamento no Estado de São Paulo. 2. ed. São Paulo, Instituto Florestal. Boletim Técnico, 1975. 53 p.

12. StRANDBERG,H.C. Aerial discavery manual. Trad. David Serrat Con gest. Barcelona, Ediciones Omega, 1957. 278 p.

13. THORLEY, G.A. et alii. Forest lands: Inventory and assesment. In American Society of Photogrammetry. Manual of Remote Sensing. Falls Church, The American Society of Photogrammetry. V. 2. Cap. 17, 1975. p. 1353-1426.

Recebido em agosto, 1981; aceito em novembro, 1981. 


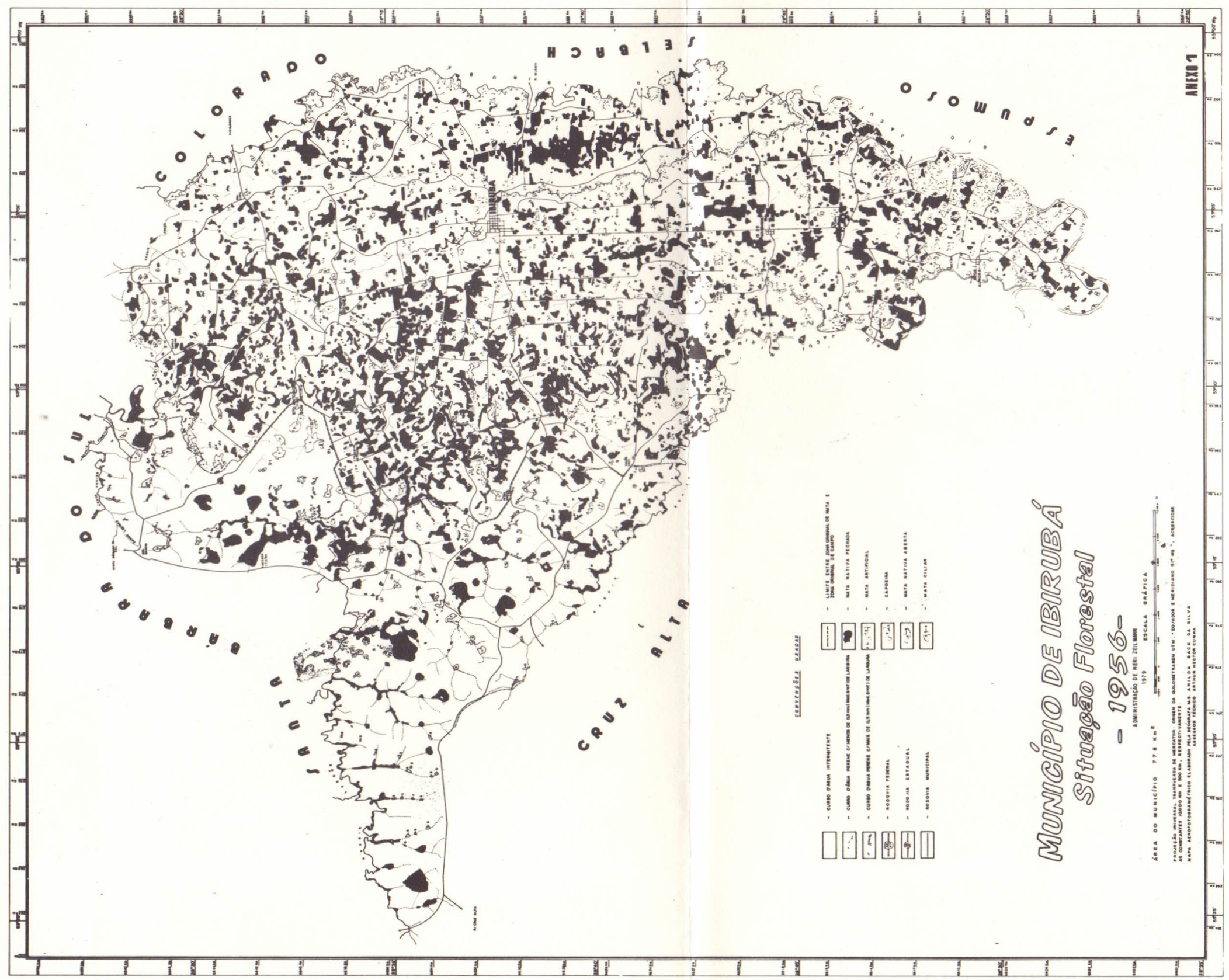





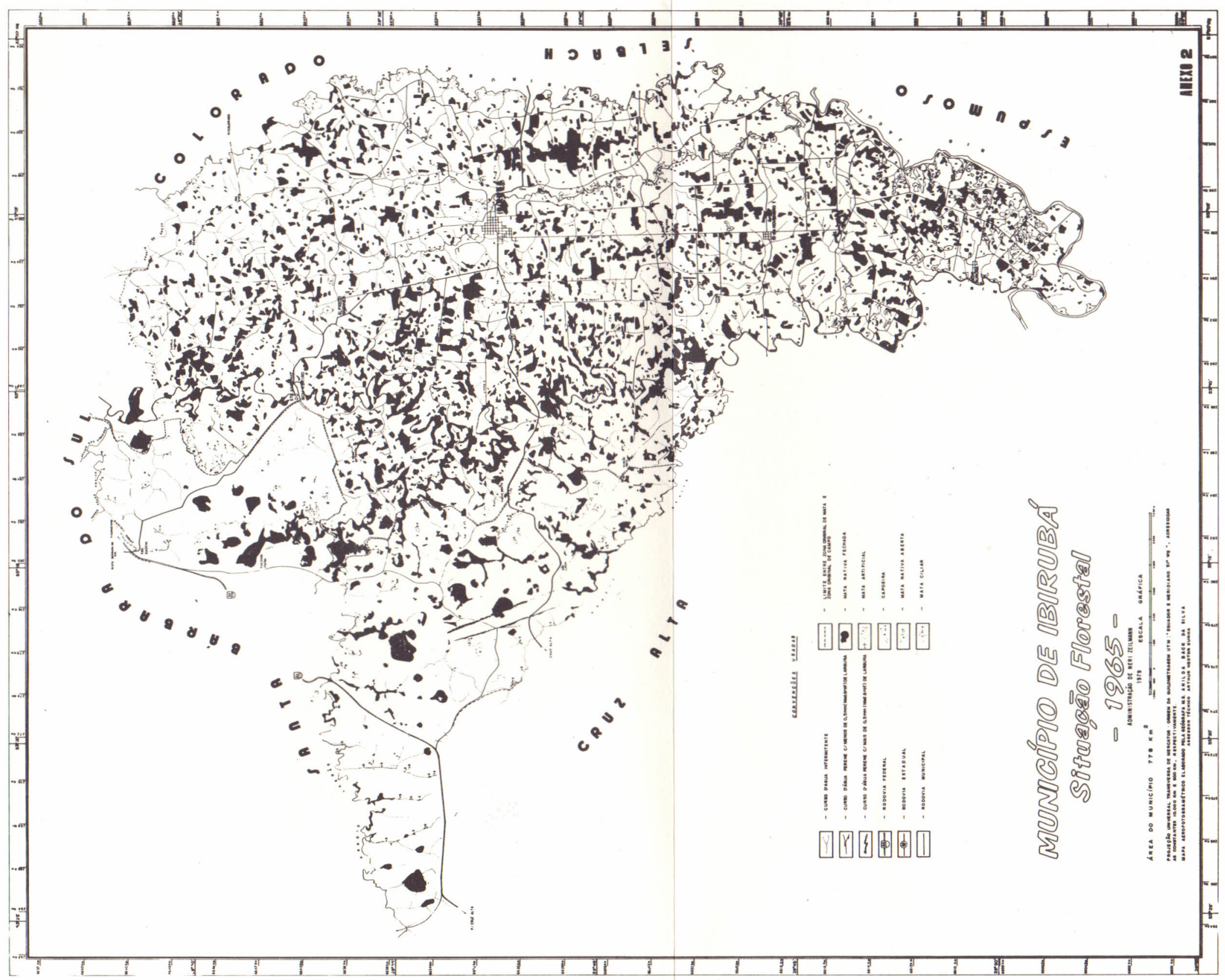





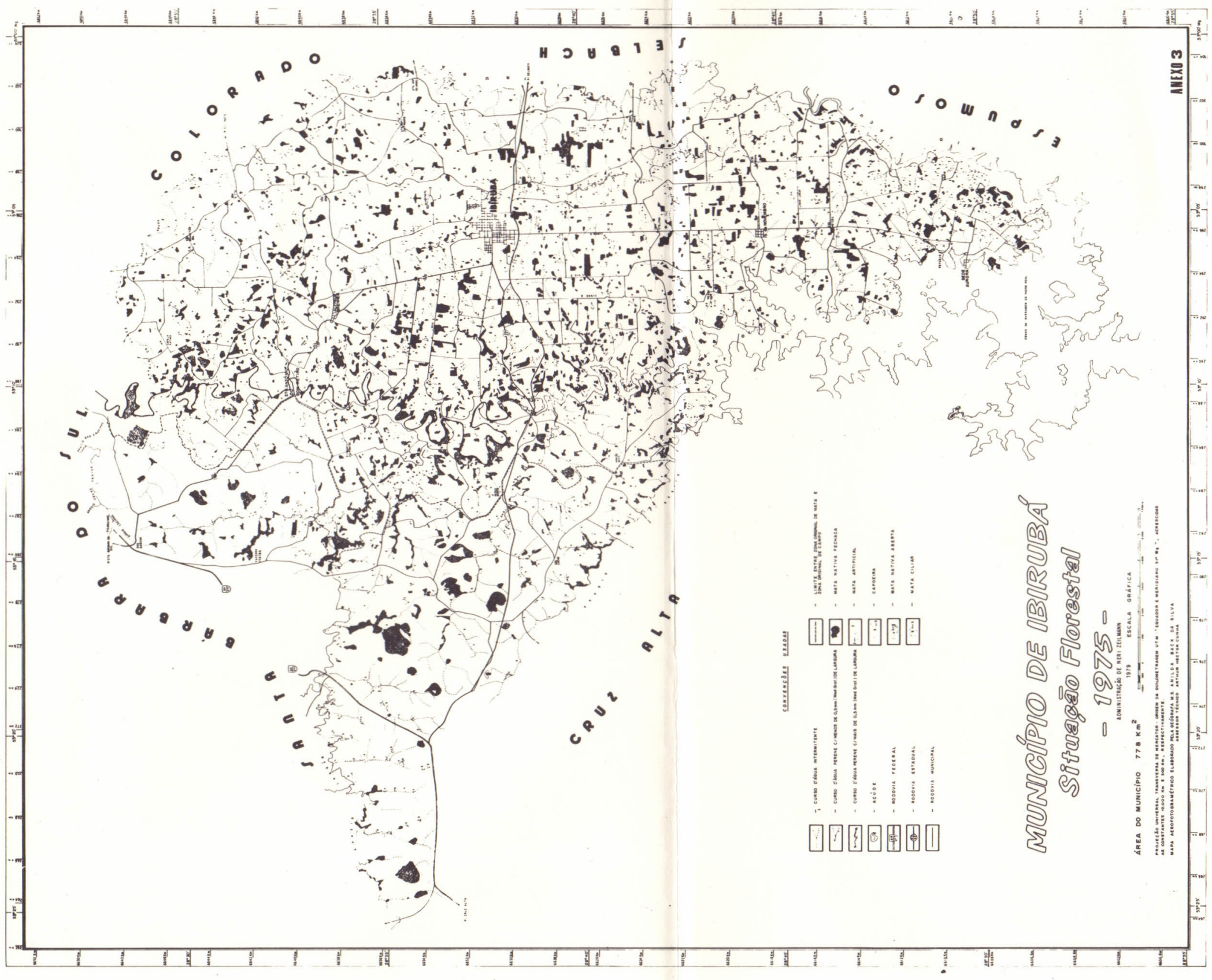





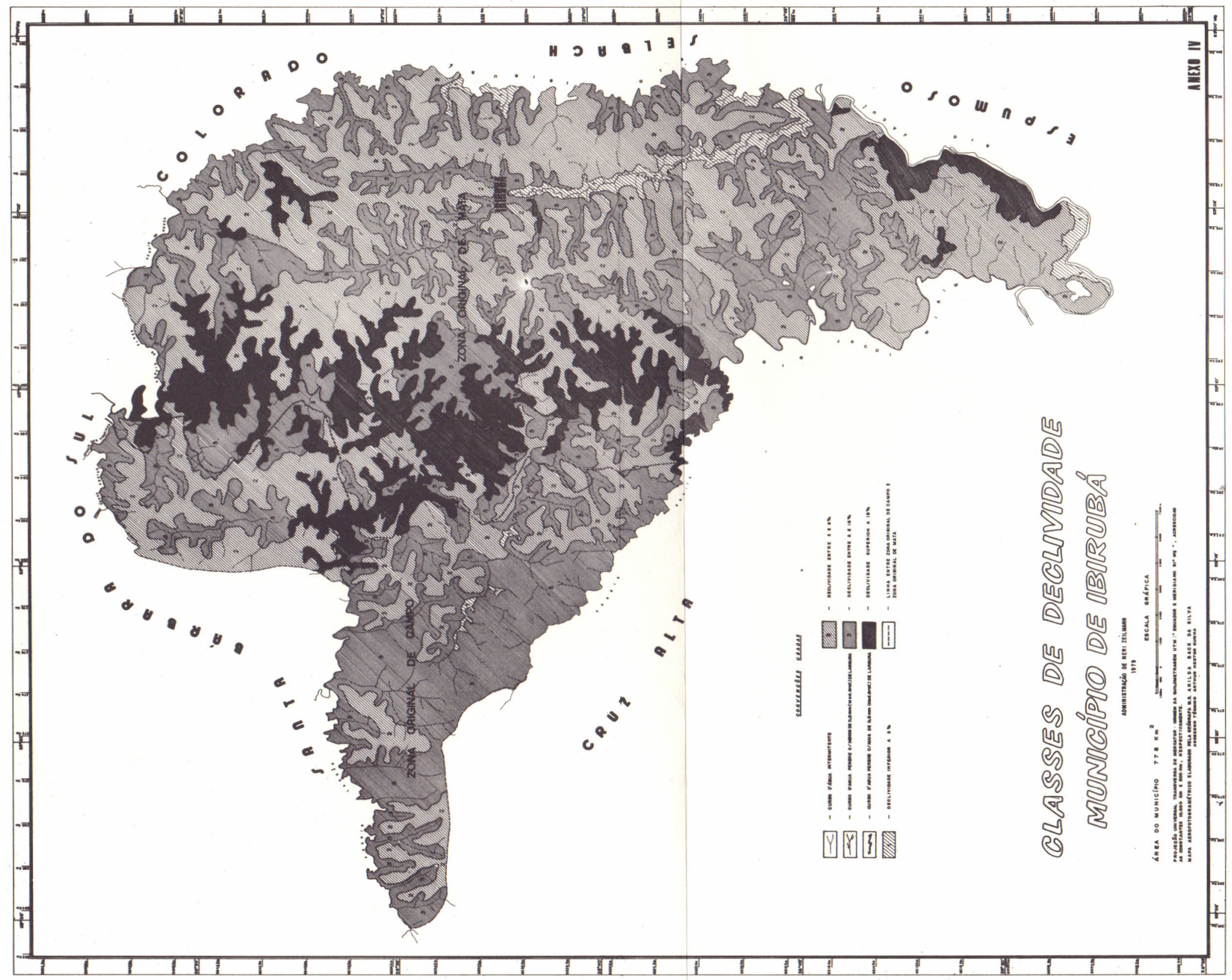


